\title{
Private LTE Network Service Management Model, based on Agile Methodologies for Big Mining Companies
}

\author{
José Valdivia-Bedregal $^{1}$, Norka Bedregal-Alpaca ${ }^{2}$, Elisa Castañeda-Huaman ${ }^{3}$ \\ Universidad Nacional de San Agustín \\ Arequipa, Perú
}

\begin{abstract}
Information technology (IT) services must generate added value for any business, either by enhancing its processes, automating its activities, or managing its resources. Using Long Term Evolution (LTE) Networks, IoT solutions and devices are able to be deployed in order to prevent safety incidents and or to online monitor performance and maintenance indicators produced by field equipment. Under the same context, implementing a private LTE network Service Management Model becomes a basic need for any company. Proposed Service Management model must be flexible enough to changes in order to accomplish high productivity demands like the ones that a Big Mining Company requires. Proposed model is based on Information Technology Infrastructure Library (ITIL) as the best known, disseminated and proven framework; additionally, it uses well known agile methodologies such as Scrum and DevOps. Along with the deployment for each of the proposed stages, a visual scheme is generated which, when it comes to a conclusion at the final stage, allows to visualize model interactions in its entirety. In addition to describing the expected results, model validation has been accomplished by an expert panel judgment under the developed topic. As a conclusion, proposed model involves a holistic approach, that is, a comprehensive approach that addresses various aspects of service management supported by a private LTE platform.
\end{abstract}

Keywords-IT service management; agile methodology; ITIL; expert judgment; LTE network

\section{INTRODUCTION}

We are living through a permanent digital revolution and the so-called digital transformation has arrived to absolutely change everything; however, many organizations have not aligned their business strategy along with IT strategy in such a way it generates value for the business. This paradigm change, this migration to a new digital world, needs to consider new ways to work; traditional verticals and un-collaborative forms have not been always successful.

The IT area is responsible for aligning its strategic objectives with those defined by the business, being able to support business performance and regulatory indicators, technical and commercial demands within a flexible and change-adaptive framework.

Thus, [1] analyzes and combines the main characteristics of IT and network management models and frameworks, with a customer focus and process based. [2] develops an IT service management model applying agile frameworks and best practice guidelines within IT management processes. At [3], the authors design and describe an information technology (IT) service management model, based on Cobit V5 framework and ITIL 2011 best practices. The author in [4] presents a comprehensive methodology for IT risk management based on ISO 31000 and ISO/IEC 27005 standards. At [5], a unified Medical and supplies management system is deployed by using agile SCRUM methodology.

In particular, big mining companies need to adapt their business strategies and models to be competitive enough. What used to be a physical focused activity and then focused at large machinery, is now moving towards knowledge and technology deployment. Under this context, implementing a private LTE network at a big mining company in addition to connecting mobile equipment will serve to remotely carry out many fundamental activities and also enable newer technologies such as augmented reality, digital twins, internet of things, among others. To achieve this objective, it is necessary to optimize Private LTE Service Management model which means a cultural change, involving change management and change adaptation; innovation and collaborative, agile and valuable efforts.

Under the described context, this article proposes a private LTE Service management model based on Agile Methodologies to improve productivity achievements according to a Big Mining company needs. In order to accomplish this, Section II displays theoretical sustentation, and Section III summarizes methodological study design. Section IV is the main part since it describes the aspects considered under ITIL framework and displays the general scheme for the proposal. The scheme allows the reader to see interrelationships between different implementation stages. Under Section V, expected results can be stated. Finally, to get a complete research validation, an expert panel with IT management experience and agile methodologies application was interviewed. Results are shown at Section VI.

\section{CONCEPTUAL FRAMEWORK}

\section{A. Digital Transformation in Mining}

Digital Transformation is a complex phenomenon in which five dimensions are identified: (a) digital leadership, (b) vision and digitalization strategy, (c) working methods, people and digital culture, (d) process digitization and decision-making, and (e) technology, data management and digital tools. 
The question is how to effectively respond to the growing society digitization, not only in terms of how to avoid becoming obsolete along competition, but also how to adapt and lead digital disruption [6].

With the fourth industrial revolution, mining operations will be marked by the use of Cyber Physical Systems, Artificial Intelligence, Internet of Things (IoT) and Big Data, for process optimization. ICT solutions applied to the mining industry define a new idea an intelligent mine, for the Mining Skills Council [7] three facets must be considered: mechanization, telecommunication-automation and optimization.

\section{B. Technology Solution: Long Term Evolution (LTE)}

Long Term Evolution, known by its acronym LTE, is a high-capacity radio technology standardized by 3GPP. LTE is a stable technology with three main features: it allows high bit rates with low latency, is cheap and easy to deploy by operators, avoids fragmentation by duplication type. LTE-M Is a type of network designed to deploy a way to communicate machines and robots beyond sensors, it is characterized because it can support a wide spectrum of M2M devices with low cost and long battery life.

\section{Information Technology Services Management (ITSM)}

ITSM is a strategic approach to design, delivery, management and improvement around ICTs within an organization. For [8], good IT service management should aim to: provide adequate quality management, increase efficiency, align business processes and ICT infrastructure, reduce risks associated with IT services and generate business value.

IT Services Management frameworks include Six Sigma, Microsoft Operations Framework, COBIT, ITIL (Information Technology Infrastructure Library).

\section{MethodolOGY}

The article can be considered as applied research. It focuses on proposing a model to address a specific problem and achieve a specific objective.

By the level of depth, it is an exploratory - descriptive research, because it analyzes and investigates specific reality aspects that have not yet been analyzed in depth and establishes a description of a specific context.

Study units are the IT strategies as business strategies support related to the three main indicators in big mining: production, cost and safety.

Data collection techniques used are: observation, interview and documentary research.

\section{PROPOSEd MODEL}

The following is a description of an stepped process to be followed by an "La Minera" IT department to adopt an agile Private LTE Network Service Management framework. The following stages have been considered: strategic, design, transition, operation and transversal processes.

Fig. 1 outlines the proposal for each of the stages considered.

\section{A. Strategic Stage Development}

At this stage, strategies are defined considering that they must be flexible enough to adapt quickly to core business strategy and maintain or achieve competitive advantages.

In relation to "Financial Management", it is proposed that management and maintenance costs must be considered at department's annual budget. To this end, annual budget has been defined for 4 years with 2 initial contracts, first one for an on-site level 1 support and the second one for a remote level 2 support provided by the telecommunications main operator. The sub-processes considered are (a) Financial Management Support, (b) Financial Planning (Budget Definition), (c) Financial Analysis and Reporting (Accounting) and (d) Service Billing (Collections).

The proposed strategy for "Business Relations" considers establishing and maintaining a client focused business relationship based on understanding the client and their needs, for which the Business Cases must be early defined and then implemented over the LTE platform. Currently under process there is: Heavy fleet management improvement, heavy fleet video solution migration, and implementing a unified geotechnical system for slope and water monitoring.

"Demand Management" considers that the implemented private LTE platform has an initial $95 \%$ coverage capacity within the operation and a bandwidth that supports $40 \mathrm{MB} / \mathrm{s}$, therefore some limitations must be analyzed later during project implementation such as the platform being able to connect only 1000 concurrent clients due to licensing or lack of band aggregation for capacity improvement.

In relation to "Service Portfolio Management", in "La Minera", initial investment made for the LTE platform can only be evaluated when reviewing the services that depend on it or that have been improved by the platform. At the moment, it is expected to increase the reliability and management capacity of the company's heavy fleet. As more services are deployed over the private LTE platform, it is relevant to perform periodical capacity reviews to analyze if services deployed over the platform are really needed or should be considered for decommission.

\section{B. Design Stage Development}

At this stage, both the design of new services and changes and improvements to existing ones must be considered; all this in order to meet the present and future requirements of the company.

In relation to "Supplier Management" three levels of support have been considered for service management. Level 1 support is provided by a company that will be in charge of all on-site support and will be responsible for monitoring and giving the first quick response to all the platform equipment and to the high criticality CPEs. Level 2 Support, which is provided by the company that rents the Band 700; this provider will be in charge of solving the problems that, due to lack of technical specialization Level 1 cannot solve. Level 3 Support is provided by the hardware and solution providers, i.e., Nokia, Cisco and Italtel. This set of support levels theoretically ensures $99.5 \%$ availability for the platform. 


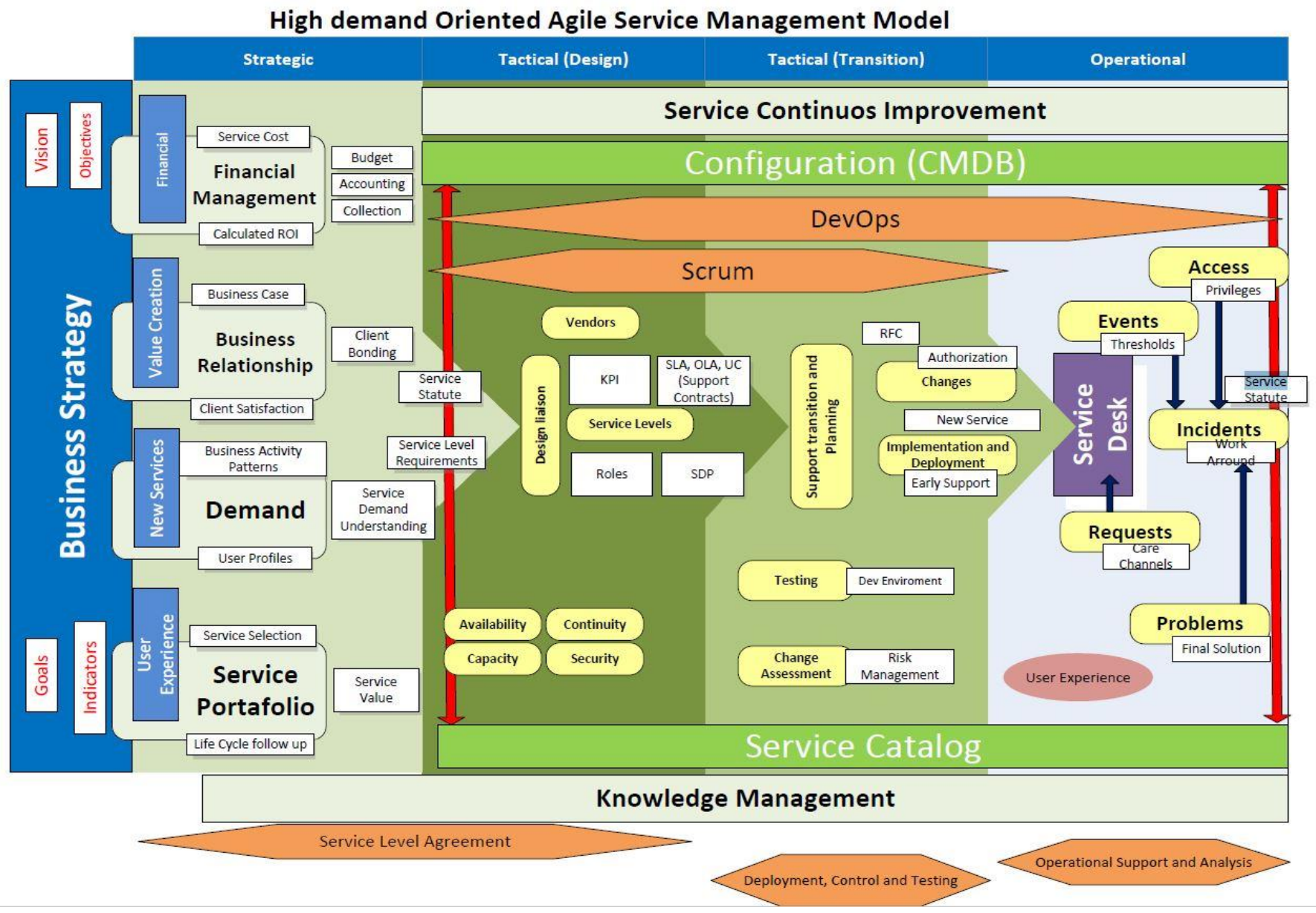

Fig. 1. General Scheme of the Proposed Model.

The "Coordination of Service Design" becomes important for the transition of new services to be hung on the platform. Service Design Packages (SDP) will be specified to assist in the delivery of the design to the transition and operation. They will primarily be used to set the parameters for future services that hang from the LTE platform.

For "Definition of Service Levels" information security is considered important when deploying an Internet of Things (IoT) platform such as the one being used on the LTE network, therefore, parameters for the platform must be defined in advance: LTE Platform Availability, LTE Platform Capacity, LTE Platform Continuity, and LTE Platform Security.

\section{Transition Stage Development}

The objective of this stage is to ensure the use of procedures that ensure the efficiency and quality of each planned change, the realization and integration of new services should take place without disturbing the operation and performance of existing services.

With regard to "Transition Planning and Support", procedures for successful deployment of new services or changes on the LTE platform must be defined. Any changes must be registered in the IT Service management platform. Two important aspects have been considered: Change Management and the Deployment and Implementation
Procedure. Change Management takes priority care of the authorizations and permissions necessary to work on the platform and reduce a possible impact, considers three levels of approval: Technical, Change CAB and Business.

The "Deployment and Implementation" process defines an early support scheme so that the area of operation is in a better position to operate the service.

For the "Validation and Testing" process, the infrastructure was installed and a haul truck was determined to start testing: the HT110 truck. This was used on the same Dispatch System that is used for the operation. Initially two PTX computer interaction screens were installed, each corresponding to one of the Connection systems: LTE and Mesh Wi-Fi. As time went by and the tests were fine-tuned, only the PTX corresponding to the LTE network was continued to use. As a result, the LTE network was faster, more reliable and with greater coverage than the one using the old Mesh Wi-Fi network.

\section{Operation Stage Development}

Ensuring that IT services are offered effectively and efficiently must meet user requirements, resolve service failures, troubleshoot issues, and perform routine operations.

For "Access Management" two types have been defined: the first at the administrator level, for the people who will manage the service and the second at the user level, which will 
be the customers of the Private LTE platform. At the administrator level, three user levels must be created. At level 1 they will have full access to all systems; all the experts in the organization are included in this group. In Level 2 and Level 3 Core Support, Italtel and Cisco teams are considered. RAN Support Level 2 and Level 3 consider the Nokia team. The user level must be operated at two levels, depending on the type of network they will connect to and the service being used.

"Event Management" focuses on the correct managing of the Network Monitoring System (NMS). The SolarWinds license is available for the corporate and industrial networks. Considering the good experiences in the use of this license; a hybrid solution of SolarWinds with Cisco Prime is being purchased for the LTE network. During the implementation of the NMS, operation thresholds must be defined. For example, client computers (CPEs) should not exceed 85\% CPU or memory usage. It is necessary to define the usage threshold that each of the APNs will have depending on the available capacity, in this case, the events must be triggered at $80 \%$ capacity usage.

"Incident Management" must provide a definitive or temporary solution to any incident that may occurs. With the confidence of having a 24/7 monitoring center, every incident will be recorded with a unique identifier in the ITSM of "La Minera". It is expected that most incidents will be logged by the NOC (Network Operation Centre) monitoring center, ensuring a proactive rather than reactive style of working. Any user can $\log$ an incident to the Service Desk considering two types: platform incidents or client incidents.

The "Request Management" as a regular process begins with the review of the application by the Digital Transformation area, who will evaluate and classify the activity in two main groups: common tasks for the business and initiatives to be consider by the Road Map.

"Problem Management" must prevent problems and incidents with the LTE network, it is possible that some customers lose connection in an area constantly, then it is part of problem management to identify the pattern of problem and seek a definitive solution, so that the same incident does not continue to occur. It is important to investigate incidents of high impact and high priority, the results of the investigation will be recorded in a Post Incident Review (PIR) document in which the root cause and corrective actions in the medium term are defined.

As a result of the operation of the service there will be multiple opinions of the business, which will depend on their past and present experiences in relation to the LTE platform and the services that work on it. For the "User Experience Management", the Service Desk will have the responsibility to implement surveys on the attention received and to provide a platform to record initiatives for potential applications or new services that could run on the platform. All this information must be registered with the ITSM: Service Now.

\section{E. Transversal to All Stage Processes Development}

Cross-cutting processes are those that interact and are relevant to all the stages described above, breaking the vertical activity flow scheme and managing to encompass the entire proposed structure. Three processes have been considered: Knowledge Management, Configuration Management, and Continuous Improvement of Services. The DevOps and Scrum methodologies will be used in the implementation of new services on the platform, focusing on not creating any affectation to the already implemented services. Both methodologies consider design and definition moments that must be addressed in order to generate good practices in the application of these methodologies.

\section{EXPECTED RESUlTS}

Generating a strategy to manage the LTE platform in order to meet the needs of "La Minera" allowed to determine processes to meet the needs of the business without losing control and correct management of the new network and identify a set of benefits derived from the use of the LTE platform and the proposed model.

The cost of implementing the projects already defined in the Road Map of the area and of the company to implement the digital transformation will be reduced. For example, the Unified Slope Monitoring project for the Geotechnical area reduced its cost by approximately $16 \%$, which is very significant, since the maintenance of the slopes represents one of the eight Fatal Risks in the business.

It will be possible to increase the volume of production, for which a project (supported by the LTE network) has already been registered, which considers the implementation of VisioFrothTM, that is, an advanced image analysis system that monitors in real time a wide variety of characteristics of the flotation cells, characteristics that can be used to adjust the level of the cells or the feed air flow, and thus guarantee maximum mineral recovery in the flotation stage.

Security risks will be reduced, as the first services already implemented on the LTE network are the Unified Slope Monitoring System and the Electric Storm Monitoring and Alert System. Both systems have a stable, easily accessible network, with the possibility of mobile positions in new locations without involving the placement of links or network cabling that complicate the work.

The risks of production losses will also be reduced, the control of the mills supported in the LTE network will prevent unplanned falls of equipment in operation, reducing maintenance times considerably and favoring the objective of ensuring the availability of SAG mills to $99.9 \%$.

It will be completed in the appropriate time with the report to entities such as the National Water Authority or the Environmental Evaluation and Control Agency, reports that involve information related to sampling. Currently the process is manual; however, taking advantage of LTE network connectivity, automatic monitoring equipment can be installed for sampling. On the other hand, with large volumes of data from automated monitoring systems, data mining processes could be implemented to establish patterns and predict future events [8].

By implementing the best practices proposed by the ITIL framework, it is expected to improve the management IT area's development and production environments; standardizing 
processes with the standard documentation indicated by ITIL will greatly improve transitions between life cycle stages and reduce early project support and incident response times.

With the application of SCRUM, implementation flexibility will be increased by having a Dynamic Backlog; each time someone wants to bring about a change in the scope of the project, a new item is added to the backlog, without having to meet with the Steering Committee. SCRUM allows the project to turn according to the real and changing needs of the business, it is expected to reduce the administrative time in the various changes of the scope of the project to a maximum of nine days which is what each Sprint will last and thereby reduce the delays by approximately $40 \%$.

By using DevOPS best practices, it is ensured that change management is strictly controlled, thus avoiding potential business impacts. Documentation and implementation processes become pillars for any implemented changes, helping to achieve the goal of eliminating known risks and reducing the likelihood of unknown risk during implementation.

\section{PROPOSAL VALIDATION}

To validate the usefulness of the proposed model, a panel of experts with experience in IT management and the application of agile methodologies were used. A professional biography of the expert was developed based on his or her background: years of experience and training, research or training actions, knowledge of the subject matter of study. For [9], the number of experts depends on the ease of accessing them or the possibility of meeting sufficient experts on the subject matter of the research, so nine experts were chosen.

The Expert Competence Coefficient $(\mathrm{k})$ was calculated as the average of two quantitative indicators the knowledge coefficient (kc) and the argumentation coefficient (ka). The kc coefficient is a measure of the level of knowledge about the investigated topic that comes from the self-assessment of each candidate. The ka coefficient was obtained from assessing its professional merits: related research, work experience, specialized reading, and knowledge of the problem situation, specialization or postgraduate studies, alignment with best practices in the sector, alignment with the business model and vision of the future. The results obtained are shown in Table I.

Of the nine experts selected, seven of them are in a high degree of competence, so it could be said that the results show high competence of the experts.

The definition of the criteria that served to build the questionnaire that would apply to the experts was based on the work of [10] and [11] who present a list of benefits related to the implementation of ITIL. Each item of the questionnaire was rated on a 5-level Likert-type scale. The Likert scale is a measurement tool that allows to measure attitudes and to know the degree of conformity of the respondent with the statements proposed to him/her [12].

Table II shows the percentage of opinions that fall within each level for each of the questions asked in the questionnaire; the last column contains the average score obtained on the item.
When calculating the average of the scores obtained for the 13 items, a value of 4.25 is obtained (red line in Fig. 2); a value that is well above the scale average of 3 points.

It can be seen in Fig. 2 that 7 of the 13 questions exceeded the average (4.25), three of them scored very close and 3 were far from the average. However, the least valued item (item 13) was the only one that was slightly below the scale average. It can be concluded then that the overall assessment of the experts is positive and in agreement with the proposal.

From the evaluations made by the experts, it is clear that they agree that the proposed model will have an impact (high or very high) on the improvement of the quality of the service delivered to the customer considering their specific needs, which will increase customer satisfaction; it will also have a strong impact on the management of IT operations as a service.

In other words, an adequate IT Service Management (ITSM) would be carried out to ensure that IT objectives are aligned with business objectives. In addition, the standardization of processes and services would be achieved through the definition of functions and documented processes for the delivery of each type of IT service.

As a measure of the reliability of the internal consistency of the items, Cronbach's $\alpha$ coefficient was calculated. An $\alpha=0.78$ was obtained, so it can be said that the evaluation made by the experts has a "Good" reliability, close to "High".

Additionally, the experts were asked to identify success factors in the implementation of the model.

TABLE I. DETERMINATION OF THE K COEFFICIENT AND THE LEVEL OF COMPETENCE OF EACH EXPERT

\begin{tabular}{|l|l|l|l|l|}
\hline Expert & $\mathrm{kc}$ & $\mathrm{ka}$ & $\mathrm{k}$ & Competence level \\
\hline E-01 & 0.8 & 0.89 & 0.845 & High \\
\hline E-02 & 0.9 & 0.9 & 0.9 & High \\
\hline E-03 & 1 & 0.91 & 0.955 & High \\
\hline E-04 & 1 & 0.96 & 0.98 & High \\
\hline E-05 & 0.8 & 0.9 & 0.85 & High \\
\hline E-06 & 0.8 & 0.76 & 0.78 & Medium \\
\hline E-07 & 0.9 & 0.84 & 0.87 & High \\
\hline E-08 & 0.7 & 0.82 & 0.76 & Medium \\
\hline E-09 & 0.9 & 0.95 & 0.925 & High \\
\hline
\end{tabular}

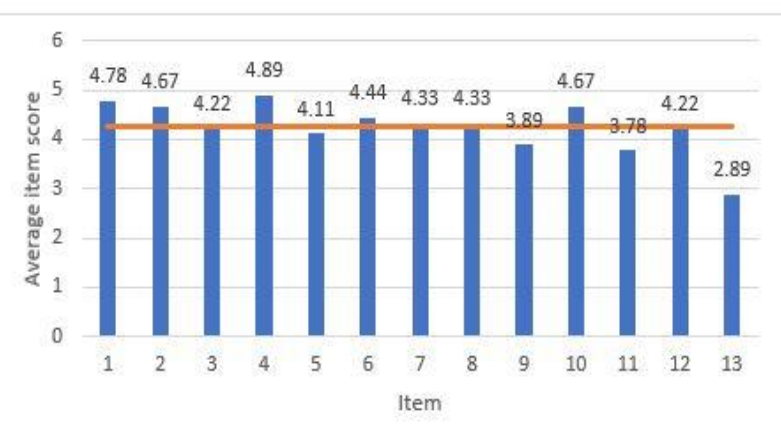

Fig. 2. Average Scores Obtained for Each Item. 
TABLE II. PERCENTAGE OF OPINIONS IN FAVOR OF EACH LEVEL

\begin{tabular}{|c|c|c|c|c|c|c|}
\hline Item & $\begin{array}{l}(1) \\
\text { Very low } \\
\text { impact }\end{array}$ & $\begin{array}{l}(2) \\
\text { Low impact }\end{array}$ & $\begin{array}{l}(3) \\
\text { Moderate } \\
\text { impact }\end{array}$ & $\begin{array}{l}\text { (4) } \\
\text { High impact }\end{array}$ & $\begin{array}{l}(5) \\
\text { Very high } \\
\text { impact }\end{array}$ & Average \\
\hline Improve quality and level of service & 0 & 0 & 0 & 22.22 & 77.78 & 4.78 \\
\hline Increase customer satisfaction & 0 & 0 & 0 & 33.33 & 66.67 & 4.67 \\
\hline Standardized and more effective processes & 0 & 0 & 0 & 77.78 & 22.22 & 4.22 \\
\hline Continuous Service Improvement & 0 & 0 & 0 & 11.11 & 88.89 & 4.89 \\
\hline Improve IT interaction with the rest of the business. & 0 & 0 & 0 & 88.89 & 11.11 & 4.11 \\
\hline Adopt a common IT process methodology & 0 & 0 & 11.11 & 33.33 & 55.56 & 4.44 \\
\hline $\begin{array}{l}\text { Alignment of services, processes and goals with the } \\
\text { requirements of the organization }\end{array}$ & 0 & 0 & 11.11 & 44.44 & 44.45 & 4.33 \\
\hline Reduce downtime in IT services & 0 & 0 & 11.11 & 44.45 & 44.44 & 4.33 \\
\hline Cost reduction & 0 & 0 & 33.33 & 44.44 & 22.23 & 3.89 \\
\hline Improve company productivity & 0 & 0 & 0 & 33.33 & 66.67 & 4.67 \\
\hline Competitive advantage over other suppliers & 0 & 0 & 44.44 & 33.33 & 22.23 & 3.78 \\
\hline Increasing IT predictability and efficiency & 0 & 0 & 11.11 & 55.56 & 33.33 & 4.22 \\
\hline Comply with regulations & 0 & 33.34 & 44.44 & 22.22 & 0 & 2.89 \\
\hline
\end{tabular}

The experts consider that the factors: Senior Management Support, Staff Training and Development, Managing the cultural change from a technological approach to a servicecentered approach and Strong focus on continuous improvement will have a strong influence (quite influential and highly influential) on the success of the model implementation (Fig. 3, 4, 5 and 6).

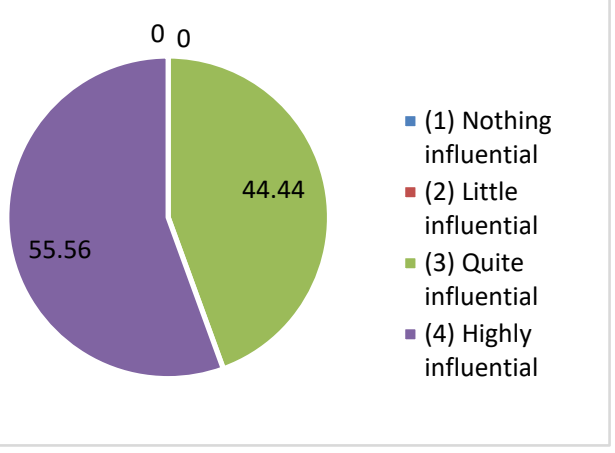

Fig. 3. Senior Management Support.

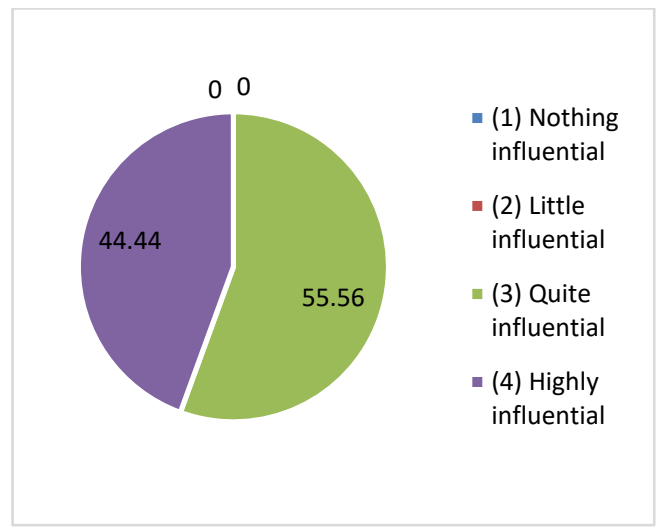

Fig. 4. Staff Training and Development.

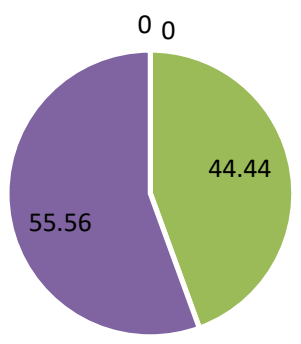

- (1) Nothing influential

- (2) Little influential

- (3) Quite influential

- (4) Highly influential

Fig. 5. Managing Cultural Change from a Technology-Driven Approach to a Service-Focused Approach.

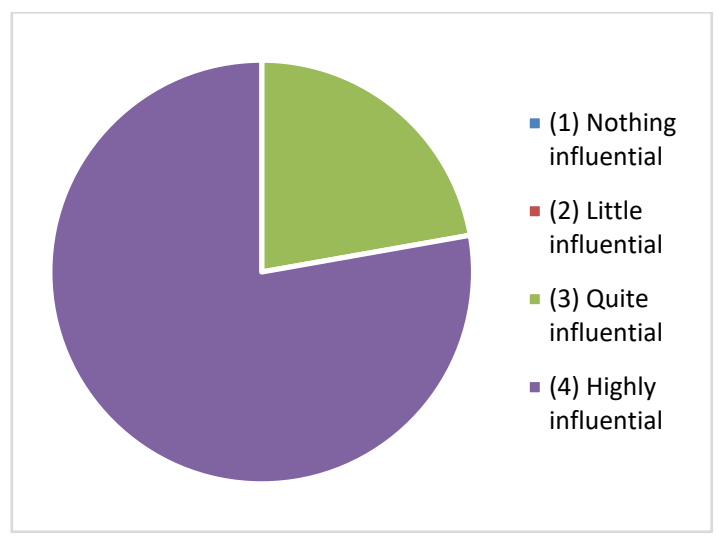

Fig. 6. Strong Focus on Continuous Improvement.

\section{CONCLUSIONS}

Considering the rapidly changing company needs, especially at the mining sector, IT functions must increasingly be integrated into day-to-day operations as in other sectors like banking. It is appropriate to adopt IT Services Management (ITSM) best practices, including the ITIL framework. 
A private LTE network Service Management Model is necessary, since the digital transformation of "La Minera" mining not only considers information systems interoperability between operation and production, but also includes important process digitalization of the mining operation environment such as: optimizing and monitoring mobile mine fleet conditions, driver behavior monitoring, anti-collision systems, IoT technologies deployment and integration, ore tracking, fleet automation, among others.

To perform what it is called digital mining, it is necessary to keep all information systems connected; as much information is available online, better informed decisions can be made; under this context, an adequate service management supported by the LTE platform is not only an IT strategy, but it becomes a business strategy.

It was possible to identify and describe various models, standards and frameworks, related to IT service management, including ITIL, Scrum, DevOps. In addition, their applicability and compatibility were identified under the context of managing services supported by LTE platform through the proposed model.

Considering that ITIL is a predictive framework of good practices at an IT service management department, which is usually applied under well-known scopes, that Scrum is an agile project management methodology oriented to less known scopes and that DevOps is a process that emphasizes communication and collaboration seeking to reduce change risk, a holistic approach model has been proposed, i.e. a comprehensive approach that addresses various aspects of service management for LTE platform supported services.

\section{ACKNOWLEDGMENT}

The authors express their appreciation to the National University of San Augustin of Arequipa for being the study center that allowed the realization of this research work.

\section{REFERENCES}

[1] R. Padilla and M. Ron, "Propuesta de modelo de gestión de infraestructura de red, basado en las mejores prácticas de gestión de TI y los modelos estándar de gestión de red- caso de estudio EP PETROECUADOR", Tesis de maestría en gestión de las comunicaciones, Escuela politécnica nacional, Quito, Ecuador, 2015.

[2] C. Navarrete and M. Ramos, "Modelo de gestión de servicios de TI para la Organización Panamericana de la Salud en el Ecuador", Tesis de maestría en gestión de las comunicaciones, Escuela politécnica nacional, Quito, Ecuador, 2016.

[3] D. López, "Modelo de gestión de los servicios de tecnología de información basado en COBIT, ITIL e ISO/IEC 27000", Revista Tecnológica - ESPOL, 30(1), 2017.

[4] F. Arévalo, I. Cedillo and S. Moscoso, "Metodología Ágil para la Gestión de Riesgos Informáticos", Revista Killkana Técnica. Vol. 1, No. 2, pp. 31-42, 2017. p-ISSN 2528-8024 / e-ISSN 2588-0888, Universidad Católica de Cuenca, 2017.

[5] H. Robalino, E. Rodríguez and A. Saldaña, "Diseño de un sistema de gestión de servicios aplicando las buenas prácticas ITIL 2011 y SCRUM en el área de Soporte de Sistemas para la empresa APC Corporación", Universidad Tecnológica del Perú, 2019.

[6] E. Schreckling and C. Steiger, "Digitalize or Drown, In book: Shaping the Digital Enterprise", August 2017. DOI: 10.1007/978-3-319-40967$2 \_1$.

[7] Consejo de Competencias Mineras, "Impacto de las nuevas tecnologías en las competencias requeridas por la industria minera", Alder Comunicaciones, Santiago, Chile, 2018.

[8] N. Bedregal-Alpaca, V. Cornejo-Aparicio, J. Zárate-Valderrama, P. Yanque-Churo, "Classification models for determining types of academic risk and predicting dropout in university students". International Journal of Advanced Computer Science and Applications (IJACSA), Volume 11 Issue $1, \quad 2020 . \quad$ DOI 10.14569/IJACSA.2020.0110133.

[9] J. Cabero Almenara and M. Llorente Cejudo, "La aplicación del juicio de experto como técnica de evaluación de las tecnologías de la información (TIC)". En Eduweb, Revista de Tecnología de Información y Comunicación en Educación, 7 (2) pp.11-22, 2013.

[10] N. Lucio and D. Gonzalez-Bañales, "Prácticas de ITSM en México y Latinoamérica 2014”, México: PITSM Latam, 2014.

[11] Kumbakara, Narayanan, "Managed IT services: the role of IT standards", Information Management \& Computer Security, Vol. 16 Iss: 4, pp.336-359, 2008.

[12] N. Bedregal-Alpaca, V. Cornejo-Aparicio, D. Tupacyupanqui-Jaén and S. Flores-Silva, "Evaluación de la percepción estudiantil en relación al uso de la plataforma Moodle desde la perspectiva del TAM", Ingeniare. Revista chilena de ingeniería versión On-line ISSN 0718-3305, Ingeniare. Rev. chil. ing. vol.27 no.4 Arica dic. 2019. DOI 10.4067/S0718-33052019000400707. 